\title{
CAPIM TROPICAL MANEJADO SOB LOTAÇÃO INTERMITENTE, SUBMETIDO A FONTES DE FÓSFORO COM DIFERENTES SOLUBILIDADES, ASSOCIADOS OU NÃO À ADUBAÇÃO COM NITROGÊNIO
}

\author{
TROPICAL GRASS MANAGED UNDER INTERMITTENT LOTATION, \\ SUBMITTED TO PHOSPHORUS SOURCES WITH DIFFERENT \\ SOLUBILITIES, ASSOCIATED OR NOT TO NITROGEN FERTILIZER
}

\author{
Camila Fernandes Domingues Duarte ${ }^{1^{*}}$ ORCID - http://orcid.org/0000-0002-9776-1353 \\ Luísa Melville Paiva1 ORCID - http://orcid.org/0000-0003-4726-943X \\ Henrique Jorge Fernandes ${ }^{1}$ ORCID - http://orcid.org/0000-0001-7617-9711 \\ Thiago Trento Biserra1 ORCID - http://orcid.org/0000-0002-6130-9787 \\ Alex Coene Fleitas ${ }^{1}$ ORCID - http://orcid.org/0000-0002-2637-0080
}

${ }^{1}$ Universidade Estadual do Mato Grosso do Sul, Aquidauna, Mato Grosso do Sul, Brasil

*Autora para correspondência - camilafernandesd@hotmail.com

\section{Resumo}

Objetivou-se avaliar as características morfogênicas e estruturais do capim-piatã submetido à lotação intermitente e adubado com fontes de fósforo de diferentes solubilidades e adubação nitrogenada. Os tratamentos foram: controle (sem aplicação de adubo fosfatado); fonte de fósforo de lenta solubilidade (FNR); fonte de fósforo de rápida solubilidade (FSS) e fonte de fósforo de solubilidade mista (FSM), associados ou não à adubação nitrogenada. Foram realizadas medições de perfilhos pré-demarcados para avaliação das características estruturais e morfogênicas das plantas. Os dados foram analisados segundo um delineamento em blocos casualizados, em arranjo fatorial 4 x 2, dentro de cada estação do ano. As médias por quadrados mínimos dos tratamentos de adubação fosfatada foram comparadas com o tratamento controle pelo teste de Dunnet, e entre si pelo teste " $t$ " e as médias de uso ou não de adubação nitrogenada foram comparadas entre si pelo teste "t" a 5\% de significância. As fontes que contém fósforo prontamente disponível, como nos tratamentos FSS e FSM, promoveram maior alongamento de folhas e colmo, bem como maior número e aparecimento de folhas, o que evidencia a importância da disponibilidade de fósforo e nitrogênio no crescimento e desenvolvimento das plantas, confirmado pelo aumento na taxa de alongamento de folhas, do aparecimento foliar e alongamento de colmo. Assim, as adubações nitrogenada e fosfatada são alternativas para a persistência e competitividade da produção animal a pasto. Em relação à fonte, o uso de fontes de fósforo com solubilidade mista fornece esse nutriente a curto, médio e longo prazo.

Palavras-chave: adubação de pastagens; caracterização morfogênica; produção em pasto; Urochloa brizantha cv.BRS Piatã.

\begin{abstract}
The objective of this study was to evaluate the morphogenic and structural characteristics of piatã grass submitted to intermittent stocking and fertilized with phosphorus sources of different solubilities and nitrogen fertilization. The treatments were: control (without phosphate fertilizer application); slow
\end{abstract}


solubility phosphorus source (FNR); fast solubility phosphorus source (FSS) and mixed solubility phosphorus source (FSM), whether or not associated with nitrogen fertilization. Measurements of pre-demarcated tillers were performed to evaluate the structural and morphogenic characteristics of the plants. Data were analyzed according to a randomized block design in a $4 \times 2$ factorial arrangement within each season. The minimum squared means of phosphate fertilizer treatments were compared with the control treatment by Dunnet test, and among themselves by the " $t$ " test and the means of use or not of nitrogen fertilization were compared to each other by the " $\mathrm{t}$ " test at $5 \%$ of significance. Sources containing readily available phosphorus, as in the FSS and FSM treatments, promoted greater leaf and stem elongation, as well as greater number and appearance of leaves, which highlights the importance of phosphorus and nitrogen availability in plant growth and development. confirmed by the increase in leaf elongation rate, leaf appearance and stem elongation. Thus, nitrogen and phosphate fertilizers are alternatives for the persistence and competitiveness of pasture livestock production. Regarding the source, the use of phosphorus sources with mixed solubility provides this nutrient in the short, medium and long term.

Keywords: morphogenic characterization; pasture fertilization; pasture production; Urochloa brizantha cv.BRS Piatan.

Recebido em: 03 de julho de 2017.

Aceito em: 08 de maio de 2019

\section{Introdução}

A produção de ruminantes no Brasil é fundamentada na alimentação a pasto em virtude da maior praticidade e economicidade. Ao se manejar e utilizar as gramíneas forrageiras de acordo com sua ecofísiologia, aperfeiçoa-se a produção de massa forrageira, garantindo sua estabilidade e persistência. A longevidade das pastagens também está relacionada com o adequado fornecimento de nutrientes às plantas. ${ }^{(1)}$

O manejo incorreto e a baixa fertilidade do solo são apontados como as principais causas da degradação das pastagens. Entre os nutrientes essenciais, o fósforo e o nitrogênio são importantes no estabelecimento, recuperação e manutenção de pastagens, especialmente na região Centro-Oeste ${ }^{(2)}$. O solo dessa região é caracterizado pela baixa fertilidade, altos teores de $\mathrm{Al}$ e baixo $\mathrm{pH}$, constituindo um cenário ineficiente para o cultivo de gramíneas e outras forrageiras de interesse zootécnico ${ }^{(3)}$.

De acordo com Pereira ${ }^{(1)}$, o desenvolvimento e crescimento das gramíneas tropicais são influenciados por fatores abióticos, especialmente a adubação. A associação de fertilizantes nitrogenados e fosfatados pode proporcionar maior incremento na produção forrageira, aumentando a produção de massa seca em resposta a essas adubações ${ }^{(4)}$. O manejo da desfolhação também modifica o comportamento das plantas forrageiras, com alterações nas características estruturais e morfogênicas.

A Urochloa brizantha BRS Piatã foi lançada no ano de 2007, após 16 anos de avaliações, com objetivo de diversificar as variedades de Brachiarias existentes no mercado ${ }^{(5)}$. Dessa forma, entender o comportamento da planta forrageira e suas características morfo-estruturais e de produção sob pastejo são importantes para a formulação de guias de manejo. Neste sentido, objetivou-se avaliar as características morfogênicas e estruturais do capim-piatã [Urochloa brizantha (Hoscht. ex. A. Rich) cv. BRS Piatã] em pastagem adubada com fontes de fósforo de diferentes solubilidades recebendo adubação nitrogenada. 


\section{Material e métodos}

O experimento foi desenvolvido em área experimental de 8 ha da Fazenda UEMS, em Aquidauana, MS. O clima da região, segundo a classificação de Köppen, é Tropical de Savana (Aw), dividido em duas estações: chuvosa (primavera e verão) e seca (outono e inverno). A área total foi subdividida em 16 piquetes de 0,5 ha cada, onde foram distribuídos os tratamentos. Os dados foram coletados na primavera (de 29 de setembro a 06 de dezembro de 2013), no verão (de 28 de dezembro de 2013 a 08 de março de 2014), no outono (de 29 de março a 31 de maio de 2014) e no inverno (de 21 de junho a 13 de setembro de 2014).

Antes de iniciada a implantação do pasto, realizou-se uma amostragem de solo para análise química do solo da área experimental (Tabela 1). Para a descrição das condições ambientais do período experimental, foram registradas mensalmente as médias de temperatura máxima, temperatura mínima, umidade relativa do ar e índice pluviométrico (Figura 1).

Tabela 1. Análise química do solo da área experimental. Fevereiro de 2012

\begin{tabular}{|c|c|c|c|c|c|c|c|c|c|c|c|c|}
\hline \multicolumn{2}{|c|}{$\mathrm{pH}$} & P & MO & $\mathrm{K}$ & $\mathrm{Ca}$ & $\mathrm{Mg}$ & $\mathrm{Ca}+\mathrm{Mg}$ & $\mathrm{H}$ & $\mathrm{Al}+\mathrm{H}$ & S & $\mathrm{T}$ & V \\
\hline $\mathrm{CaCl}_{2}$ & Água & $\mathrm{Mg} / \mathrm{dm}^{2}$ & $\mathrm{~g} / \mathrm{dm}^{2}$ & \multicolumn{8}{|c|}{$\mathrm{Cmol} / \mathrm{dm}^{3}$} & $\%$ \\
\hline 5,11 & 5,74 & 43,75 & 18,05 & 0,8 & 2,2 & 0,9 & 3,05 & 3,2 & 3,17 & 3,8 & 7 & 54,71 \\
\hline
\end{tabular}

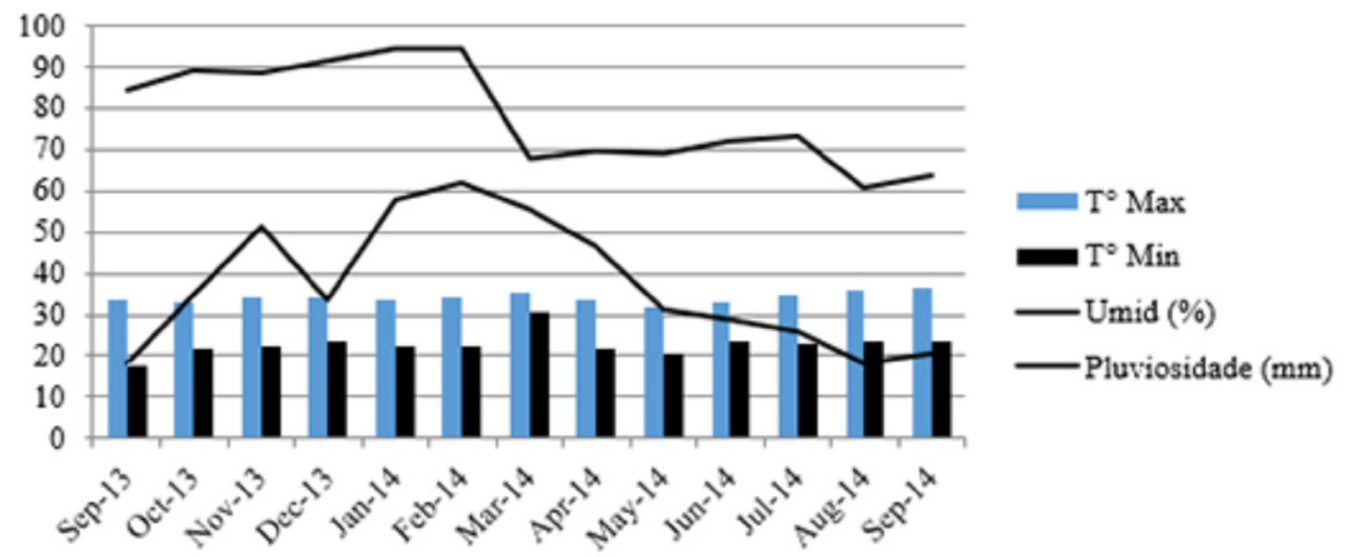

Figura 1. Dados climáticos (temperatura, umidade e pluviosidade) observados durante o período experimental.

Foram realizadas duas gradagens para limpeza e preparo da área e, posteriormente, semeadura com $10 \mathrm{~kg} \mathrm{ha}^{-1}$ de sementes de capim-piatã puras viáveis. No momento da implantação (abril de 2012), foram distribuídos os tratamentos de adubação fosfatada e, em 10 de abril de 2013, os tratamentos de adubação nitrogenada. Os tratamentos consistiram em tratamento controle (sem aplicação de adubo fosfatado); fonte de fósforo de lenta solubilidade (FNR); fonte de fósforo de rápida solubilidade (FSS) e fonte de fósforo de solubilidade mista (FSM), associados ou não à adubação nitrogenada. Os piquetes que receberam o tratamento de solubilidade rápida de fósforo foram adubados com $150 \mathrm{~kg}$ $\mathrm{ha}^{-1}$ de Superfosfato Simples com $18 \%$ de $\mathrm{P}_{2} \mathrm{O}_{5}$. Os piquetes do tratamento de solubilidade lenta de fósforo foram adubados com 103,5 $\mathrm{kg} \mathrm{ha}^{-1}$ de Fosfato Natural Reativo com $28 \%$ de $\mathrm{P}_{2} \mathrm{O}_{5}$. O terceiro tratamento consistiu na fonte de solubilidade mista de fósforo, assim os piquetes desse tratamento foram adubados com $97 \mathrm{~kg} \mathrm{ha}^{-1}$ de $\mathrm{FH}$ pastagem ${ }^{\circledR} \operatorname{com} 31 \%$ de $\mathrm{P}_{2} \mathrm{O}_{5}$. Todas as fontes de fósforo foram distribuídas a lanço e fornecidas em média $29 \mathrm{~kg}$ de $\mathrm{P}_{2} \mathrm{O}_{5}$ em todos os piquetes e tratamentos. 
A adubação nitrogenada foi realizada utilizando ureia protegida através do adubo comercial Nitro Mais ${ }^{\circledR}$, na dosagem equivalente ao fornecimento de $100 \mathrm{~kg} \mathrm{~N} \mathrm{ha}^{-1}$ parcelados em duas doses (abril e dezembro de 2013). Em fevereiro de 2013, foram realizadas amostragens de solo de cada piquete para quantificar o teor médio de fósforo de cada tratamento (Tabela 2).

No mês de julho de 2013, iniciou-se a ocupação dos piquetes com 32 bovinos machos inteiros recémdesmamados pesando, em média, $180 \mathrm{~kg}$.

Tabela 2. Comparação do teor de fósforo inicial e no ano de 2013 no solo

\begin{tabular}{ccc}
\hline Tratamentos & Teor de P incial & Teor de P em 2013 \\
\hline & $\mathbf{M g} / \mathbf{d m}^{\mathbf{3}}$ & $\mathbf{M g} / \mathbf{d m}^{\mathbf{3}}$ \\
\hline FNR & 43,7 & 29,3 \\
FSS & 43,7 & 46,5 \\
FSM & 43,7 & 55,4 \\
\hline Controle & 43,7 & 35,4 \\
\hline
\end{tabular}

FNR: Fonte de Solubilidade Lenta; FSS: Fonte de Solubilidade Rápida e FSM: Fonte de Solubilidade Mista.

Os animais foram rotacionados nos piquetes por bloco, com altura média de entrada de $35 \mathrm{~cm}$ e altura de saída de $20 \mathrm{~cm}$ em média. As medições de altura foram realizadas duas vezes por semana, às segundas e sextas-feiras (Tabela 3).

Tabela 3. Média das alturas de pré e pós-pastejo reis e número de ciclo de pastejo de cada tratamento

\begin{tabular}{ccccccc}
\hline & \multicolumn{2}{c}{ Real } & \multicolumn{4}{c}{ Ciclo de Pastejo } \\
\hline & Altura Pré-Pastejo & Altura Pós-Patejo & Primavera & Verão & Outono & Inverno \\
\hline Controle & 29,5 & 21 & 2 & 2 & 1 & 1 \\
\hline FNR & 29,8 & 19 & 2 & 2 & 2 & 1 \\
\hline FSS & 31 & 19,5 & 4 & 5 & 3 & 4 \\
\hline FMS & 30,5 & 19,7 & 4 & 6 & 6 & 4 \\
\hline
\end{tabular}

FNR: Fonte de Solubilidade Lenta; FSS: Fonte de Solubilidade Rápida e FSM: Fonte de Solubilidade Mista.

A avaliação das forrageiras foi realizada pela caracterização morfogênica e estrutural. Para a avaliação morfogênica, foram demarcados, a cada estação e em cada piquete, 12 perfilhos distribuídos em três sítios por piquete. Esses perfilhos foram identificados com fios plásticos coloridos e cada sítio foi demarcado por uma régua transecta de vergalhão, com comprimento de dois metros e marcada a cada $50 \mathrm{~cm}$.

Com auxílio de régua milimetrada, foram medidos o comprimento das folhas verdes e do pseudocolmo. Nas folhas em expansão, a mensuração foi realizada a partir da lígula da última folha, expandida como referencial. Nas folhas expandidas, foram medidas da lígula até a ponta da folha verde. O comprimento do pseudocolmo foi realizado medindo a distância do solo até a lígula da folha mais jovem completamente expandida. Foram realizados ainda os registros: folhas expandidas, folhas cortadas e folhas mortas. Essas medidas foram utilizadas na determinação das seguintes taxas:

- Taxa de aparecimento foliar (TApF): quociente entre o número de folhas por perfilho surgidas no período avaliado e o número de dias do período;

- Filocrono (Filo): número de dias que duas folhas crescem num mesmo perfilho;

- Taxa de alongamento foliar (Tal F): relação entre o somatório de todo alongamento das lâminas foliares $(\mathrm{cm})$ e o número de dias do período de avaliação ((comprimento final - comprimento inicial) $/ \mathrm{n}^{\circ}$ de dias 
contabilizados);

- Taxa de senescência de folhas (TSeF): variação média no comprimento da porção senescente da folha, resultado do produto entre o comprimento da lâmina foliar senescente e a proporção de tecido senescente correspondente, observada ao longo do período de avaliação;

• Número de folhas vivas (NFV): contagem do número de folhas vivas, não senescentes;

- Duração de vida das folhas (DVF): NFV X Filo e,

- Taxa de alongamento de colmo (TAlC): diferença do comprimento do pseudocolmo no final e no início do período experimental pelo número de dias deste ((comprimento final - comprimento inicial) $/ \mathrm{n}^{\circ}$ de dias contabilizados).

A densidade populacional de perfilhos foi obtida por meio da contagem de perfilhos em duas áreas de $0,25 \mathrm{~m}^{2}$ delimitadas em cada piquete. A contagem dos perfilhos foi realizada a cada 28 dias e os perfilhos foram classificados em perfilhos basilares (DPPb) ou aéreos (DPPa), de acordo com a gema que deu origem ao mesmo; em reprodutivos (DPPr), quando apresentaram inflorescência, e em perfilhos mortos. Cada geração de perfilhos foi demarcada com uma cor de arame colorido e os perfilhos aéreos com um arame branco junto ao colorido daquela geração. Para a determinação da dinâmica de perfilhamento, foram estimadas as taxas de aparecimento, mortalidade e sobrevivências de perfilhos (TxAp, TxMort e TxSobr). Também foi calculado o índice de estabilidade da população de perfilhos (IE) ${ }^{(6)}$ :

- TAP (taxa de aparecimento de perfilhos $)=\left(\left(\left(\mathrm{n}^{\mathrm{o}}\right.\right.\right.$ de perfilhos novos $\operatorname{marcados} / \mathrm{n}^{\circ}$ total de perfilhos vivos na marcação anterior) $\mathrm{x} 100) / \mathrm{n}^{\mathrm{o}}$ de dias do ciclo);

- TMP (taxa de mortalidade de perfilhos $)=\left(\left(\left(\mathrm{n}^{\mathrm{o}}\right.\right.\right.$ de perfilhos $\operatorname{mortos} / \mathrm{n}^{\mathrm{o}}$ total de perfilhos vivos na marcação anterior) x100) $/ \mathrm{n}^{\mathrm{o}}$ de dias do ciclo);

- TSP (taxa de sobrevivência de perfilhos) = 1- TMP;

- Índice de estabilidade $=$ TSP $x(1+\mathrm{TAP})$.

O monitoramento da interceptação da luz incidente foi realizado utilizando o AccuPAR Linear PAR/LAI ceptometer, com o qual foram realizadas leituras em seis pontos aleatórios em zigue e zague parcela ${ }^{-1}$ a cada 14 dias no período de maior intensidade luminosa (a partir das onze horas da manhã) e sem a presença de nuvens. Em cada ponto foi realizado uma leitura acima do dossel forrageiro e outra no nível do solo. $\mathrm{O}$ índice de área foliar (IAF) também foi estimado pelo mesmo aparelho.

Os dados foram analisados utilizando-se o software SAS University (SAS Institute Inc., Cary, CA, EUA), segundo um delineamento em blocos casualizados em arranjo fatorial 4 x 2 (quatro tipos de adubo fosfatado e uso ou não de adubação nitrogenada), dentro de cada estação do ano. A premissa de independência dos resultados por estação do ano foi confirmada pela determinação da significância do efeito da interação entre tratamentos x estação utilizando-se o PROC GLIMMIX deste software.

Quando cabível, as médias por quadrados mínimos dos tratamentos de adubação fosfatada foram comparadas com o tratamento controle pelo teste de Dunnet, e entre si pelo teste " $\mathrm{t}$ " de student, e as médias de uso ou não de adubação nitrogenada foram comparadas entre si pelo teste " $t$ " de student. Utilizou-se o PROC GLM nestas análises, e adotou-se o nível de significância de 5\% em todas as comparações estatísticas. 


\section{Resultados e discussão}

Não se observou efeito de interação entre os fatores estudados em nenhuma das variáveis avaliadas. Desse modo, não houve a necessidade de desdobramentos. Observou-se efeito $(\mathrm{P}<0,05)$ da adubação nitrogenada na TAlF, TAlC, NFV e TApF das plantas (Tabela 4). Este nutriente, quando disponibilizado e absorvido pelas plantas forrageiras, se liga às cadeias carbonadas aumentando o desenvolvimento de novos tecidos. Justifica-se assim o incremento de $15,9 \%, 15,7 \%, 23,5 \%$ e $81,3 \%$ nas respectivas características.

Tabela 4. Taxa de alongamento foliar (TAIF), taxa de alongamento de colmo (TAlC), duração de vida das folhas (DVF), número de folhas vivas (NFV), taxa de aparecimento foliar (TApF) e filocrono do capim-piatã adubados com fontes de fósforo de diferente solubilidade na primavera e verão de 2013

\begin{tabular}{|c|c|c|c|c|c|c|c|c|}
\hline \multirow{3}{*}{ Característica } & \multicolumn{6}{|c|}{ Tratamentos } & \multirow{3}{*}{ C.V. } & \multirow{3}{*}{$\begin{array}{c}\text { Valor-P } \\
\text { Efeito do } \mathbf{N}\end{array}$} \\
\hline & \multirow[b]{2}{*}{ Controle } & \multicolumn{3}{|c|}{ Fontes de Fósforo } & \multirow{2}{*}{$0 \mathrm{~kg} \mathrm{ha}^{-1} \mathrm{~N}$} & \multirow{2}{*}{$100 \mathrm{~kg} \mathrm{ha}^{-1}$} & & \\
\hline & & FNR & FSS & FSM & & & & \\
\hline \multicolumn{9}{|c|}{ Primavera } \\
\hline TAIF (cm dis') & 2,05 & $1,25 \mathrm{c}^{*}$ & $3,82 b^{*}$ & $4,28 \mathrm{a}^{*}$ & 2,64 & 3,06 & 9,00 & 0,01 \\
\hline TAlC (cm dis') & 1,13 & $0,80 \mathrm{c}$ & $1,64 b^{*}$ & $1,91 \mathrm{a}^{*}$ & 1,27 & 1,47 & 11,45 & 0,05 \\
\hline DVF (dias) & 53,47 & $49,2 \mathrm{c}$ & $90,7 \mathrm{a}^{*}$ & $66,5 b$ & 61,10 & 68,90 & 11,90 & 0,08 \\
\hline $\begin{array}{l}\text { NFV (nimero de } \\
\text { tollas vivas perfilho") }\end{array}$ & 2,83 & $3,08 \mathrm{c}$ & $5,08 b^{*}$ & $6,83 \mathrm{a}^{8}$ & 3,95 & 4,95 & 9,33 & 0,002 \\
\hline TApF & 0,14 & $0,10 \mathrm{c}$ & $0,25 \mathrm{ab}$ & $0,43 \mathrm{a}^{*}$ & 0,16 & 0,29 & 50,58 & 0,05 \\
\hline TseF & 4,67 & $3,28^{2}$ & $3,64^{2}$ & $3,12 \mathrm{a}$ & 3,66 & 3,69 & 36,96 & 0,95 \\
\hline Filocrono & 8,28 & $6,47 \mathrm{c}$ & $11,0 \mathrm{~b}$ & $17,9 \mathrm{a}^{*}$ & 10,72 & 11,1 & 19,32 & 0,78 \\
\hline \multicolumn{9}{|c|}{ Verão } \\
\hline TAIF (cm dis') & 2,81 & $1,50 \mathrm{c}^{*}$ & $3,92 b^{*}$ & $5,15 \mathrm{a}^{*}$ & 3,24 & 3,45 & 1,22 & $<.0001$ \\
\hline TAIC ( $\left.\mathrm{cm} \mathrm{dis}^{-1}\right)$ & 1,22 & $1,31 \mathrm{c}$ & $1,92 b^{*}$ & $2,26 \mathrm{a}^{*}$ & 1,58 & 1,77 & 2,66 & 0,002 \\
\hline DVF (dias) & 50,09 & $40,3 \mathrm{c}^{*}$ & $71,1 b^{*}$ & $80,0 a^{8}$ & 59,77 & 61,0 & 0,89 & 0,004 \\
\hline $\begin{array}{l}\text { NFV (zimero de } \\
\text { follass vivas perfilho') }\end{array}$ & 3,06 & $1,59 \mathrm{c}^{*}$ & $5,56 \mathrm{~b}^{*}$ & $7,81 \mathrm{a}^{*}$ & 4,08 & 4,94 & 10,90 & 0,01 \\
\hline TApF & 0,23 & $0,17 \mathrm{c}^{*}$ & $0,46 b^{*}$ & $0,65 \mathrm{a}^{*}$ & 0,34 & 0,41 & 5,78 & 0,001 \\
\hline TseF & 3,20 & $3,18^{2}$ & $3,20^{2}$ & $3,42 \mathrm{a}$ & 3,00 & 3,49 & 5,44 & 0,001 \\
\hline Filocrono & 8,29 & $5,77 \mathrm{c}^{*}$ & $9,97 \mathrm{~b}^{*}$ & $16,2 \mathrm{a}^{*}$ & 9,91 & 10,2 & 0,69 & 0,0002 \\
\hline \multicolumn{9}{|c|}{$\begin{array}{l}\text { FNR: Fonte de Solubilidade Lenta; FSS: Fonte de Solubilidade Rápida e FSM: Fonte de Solubilidade Mista. } \\
{ }^{1} \text { Médias de Fontes de fósforo seguidas de um * diferem do tratamento controle pelo teste de Dunnet ao nivel de } 5 \% \text {. } \\
{ }^{2} \text { Médias de Fontes de fósforo seguidas de letras minúsculas distintas diferem entre si pelo teste " } t \text { " ao nivel de } 5 \% \text {. }\end{array}$} \\
\hline
\end{tabular}

O N compõe a estrutura das proteínas e dos ácidos nucléicos, participantes da síntese de compostos orgânicos que constituem a estrutura vegetal, importantes no desenvolvimento da planta ${ }^{(7)}$. Plantas com o aporte suficiente de $\mathrm{N}$ apresentam valores três a quatro vezes maiores na TAlF em relação àquelas não adubadas $^{(8)}$. A TAlF respondeu positivamente à adubação nitrogenada, possivelmente devido à deposição do $\mathrm{N}$ na zona de divisão celular ${ }^{(9)}$.

$\mathrm{O}$ fornecimento de $\mathrm{N}$ proporcionou uma pequena diferença na TAlF e TAlC entre os tratamentos com e sem adubação nitrogenada, visto que essa adubação pode proporcionar incrementos acima de $60 \%$ no desenvolvimento forrageiro ${ }^{(10)}$. Infere-se que o baixo índice pluviométrico do período experimental (Figura 1) tenha limitado a resposta da adubação nitrogenada uma vez que, em condições normais, a pluviosidade 
média do período é de $450 \mathrm{~mm}$. No entanto, Fagundes et al. ${ }^{(11)}$ observaram que, em condições climáticas favoráveis, o nitrogênio é rapidamente utilizado pela planta, aumentando o alongamento e o aparecimento de novas folhas (TApF).

Grant ${ }^{(12)}$ mencionou uma correlação negativa entre o alongamento de colmo e o aparecimento de novas folhas. Entretanto, isso não acontece em gramíneas tropicais, uma vez que a TAlC é expressiva nessas gramíneas, o que se percebe nesse experimento, as duas taxas aumentaram simultaneamente. Assim, o maior comprimento da bainha proporcionado pela adubação nitrogenada foi acompanhado pelo aumento do aparecimento de folhas. Lemaire e Chapman ${ }^{(13)}$ relataram a eficiência do uso de adubação com nitrogênio sobre a TApF, e sua relação com o número final de folhas vivas.

Comparando as fontes de fósforo de diferentes solubilidades, verificou-se resultados benéficos dos tratamentos com P prontamente disponível, FSM e FSS. O pH do solo, possivelmente, afetou esses resultados. Solos com pH entre 5 e 7 melhoram a eficiência de resposta dos fosfatos solúveis em virtude da

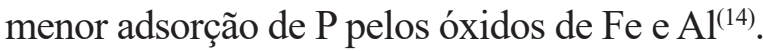

A maior TAlF foi observada no tratamento FSM, com incremento acima de $100 \%$ em relação as plantas do tratamento FNR. A diferença entre os resultados pode ter sido influenciada pela capacidade do fertilizante de reagir com as partículas do solo. Santos et al. ${ }^{(15)}$ observaram que o $\mathrm{pH}$, a capacidade de retenção do $\mathrm{Pe}$ o teor de matéria orgânica do solo influenciam na quantidade de P que será potencialmente disponibilizado para as plantas. $\mathrm{O}$ tratamento FSS proporcionou maior duração de vida das folhas, superando o tratamento controle em $69,5 \%$. Segundo Marschner ${ }^{(16)}$, o fósforo no solo estimula o desenvolvimento das raízes, pois exerce influência na taxa fotossintética. Assim, quando não há déficit desse nutriente, as folhas produzem maior quantidade de fotoassimilados, mantendo-se verdes por mais tempo.

A fonte de solubilidade mista elevou o filocrono acima de $100 \%$. Infere-se que a disponibilidade de $\mathrm{P}$ para as plantas melhorou o desenvolvimento das mesmas, uma vez que, nesse tratamento, observou-se maior TAlC e filocrono. De acordo com Skinner e Nelson ${ }^{(17)}$, um maior filocrono geralmente ocorre com o aumento da idade das plantas, maior TAlC ou altura da planta. Dessa forma, eleva-se o tempo necessário para a folha percorrer a distância entre o meristema apical e a extremidade do colmo formado pelas folhas mais velhas.

Observou-se efeito $(\mathrm{P}<0,05)$ da adubação nitrogenada em todas as características estruturais e morfogênicas (Tabela 3). Esta resposta do $\mathrm{N}$ pode ser justificada pela maior eficiência desse nutriente no verão, uma vez que, nessas condições, o crescimento das plantas forrageiras é acelerado, ocorrendo provavelmente uma maior taxa de absorção do N. Nesta situação, a maior disponibilidade de $\mathrm{N}$ pode ter promovido incrementos na fotossíntese, influenciando todos os aspectos morfofisiológicos.

A adubação nitrogenada aumentou a TAlF e a TAlC. Esse aumento é esperado sempre que se usa o fertilizante nitrogenado, como Volenec e Nelson ${ }^{(18)}$. Esses autores observaram que o fornecimento de $\mathrm{N}$ aumentou o número de células na zona de alongamento, estimulando a divisão celular, mostrando que esse nutriente é indispensável na dinâmica de crescimento e expansão dos órgãos da planta. Esses autores também observaram que o alongamento foliar é dependente da zona de alongamento e das zonas de divisão celular, caracterizadas pela grande demanda e acúmulo de N, o que demonstra a importância do N neste processo fisiológico da planta.

Neste sentido, Pereira ${ }^{(1)}$ afirmou ainda que a combinação do genótipo com os fatores abióticos e bióticos determinam e flexibilizam a morfogênese nas forrageiras. Assim, em condições ambientais favoráveis ao crescimento e desenvolvimento das plantas forrageiras, os efeitos positivos da adubação nitrogenada serão expressivos. 
De acordo com Alexandrino et al. ${ }^{(19)}$, as plantas Urochloa brizantha são sensíveis a adubação nitrogenada, com resultados positivos na TAlF. A TAlF é uma característica de grande relevância no manejo das pastagens em função do fluxo de tecido, estando diretamente relacionado com a produção forrageira. $\mathrm{O}$ alongamento de colmo é uma característica que, assim como a TAlF, modifica a estrutura do pasto. No entanto, um maior alongamento de colmo não é desejável, podendo modificar negativamente a relação folha-colmo. Resultados semelhantes foram apresentados por Dourado et al. ${ }^{(20)}$, que observaram que a adubação nitrogenada associada à baixa frequência e à baixa intensidade de pastejo contribuíram para o aumento do alongamento do colmo.

A adubação nitrogenada aumentou também a DVF no verão (60,9 dias) (Tabela 4). Na ausência da adubação, as plantas apresentaram duração de vida de 59,77 dias, um aumento de 2,1\%. O N pode ter prolongado a vida das folhas, evitando a mobilização interna do nutriente das folhas mais velhas. A DVF é de extrema importância para o manejo das pastagens por determinar o equilíbrio entre o crescimento e senescência. Neste sentido, o aumento na DVF proporcionado pelo uso da adubação nitrogenada pode aumentar os dias de pastejo, visto que as perdas por senescência não irão acontecer precocemente, diminuindo as perdas de material verde.

Houve efeito $(\mathrm{P}<0,05)$ da adubação nitrogenada sobre o NFV e TApF do capim-piatã. Essa resposta pode estar associada ao estímulo proporcionado pelo $\mathrm{N}$ e pela temperatura que, por sua vez, regulam a atividade meristemática. No verão, a adubação nitrogenada aumentou em 14,7\% a TSeF devido ao maior fluxo e renovação de tecidos. Apesar de um maior TseF, ocorreu também uma maior TapF, equilibrando os processos produtivos da pastagem.

Texeira et al. ${ }^{(21)}$ evidenciaram um aumento na TSeF no verão e na primavera. Os autores justificaram esse acréscimo pelo maior índice pluviométrico, o que teria ocasionado um maior incremento de biomassa. Também Alexandrino et al. ${ }^{(19)}$ observaram elevada TSeF em função do efeito do $\mathrm{N}$ na planta. Os autores concluíram que o efeito da adubação nitrogenada sobre essa variável é dependente do estádio fisiológico e do status de $\mathrm{N}$ da planta.

Observou-se também efeito $(\mathrm{P}<0,05)$ da adubação nitrogenada no filocrono do capim-piatã. $\mathrm{O}$ nitrogênio acelerou o crescimento do perfilho, tornando os eventos fisiológicos mais rápidos, acelerando também o desenvolvimento do filocrono, aumentando a distância entre o meristema apical e a extremidade do colmo.

Em relação aos tratamentos de adubação fosfatada, os resultados do tratamento FMS foram superiores aos do tratamento controle em todas as características avaliadas, exceto na TSeF (Tabela 4). Isto pode ser atribuído às diversas funções do fósforo dentro das células das plantas, cuja atuação foi potencializada pela maior solubilidade da fonte utilizada.

A diferença de resultados entre os tratamentos que possuem fósforo prontamente disponível (FSM e FSS) está associada à baixa quantidade de P presente no solo dos piquetes do tratamento FSS após um ano e meio da adubação, uma vez que o superfosfato simples disponibiliza $P$ no solo rapidamente após a aplicação, com o decorrer do experimento. Contudo, a quantidade disponível de $\mathrm{P}$ já pode ter sido totalmente disponibilizada para as plantas.

A TAlF e TAlC das plantas que receberam o tratamento FSM diferiram dos demais tratamentos $(\mathrm{P}<0,05)$. Esse maior alongamento das folhas e colmo possivelmente é decorrente da boa disponibilidade de $\mathrm{P}$ às plantas, relevante em todos os processos morfofisiológicos, sendo vital para a formação do ATP (adenosinatrifosfato), principal fonte de energia. O valor médio da TAlF nesse tratamento foi duas vezes superior ao da TAlC. Observa-se assim perfilhos com maior quantidade de folhas e baixa contribuição do colmo. Para Santos et al. ${ }^{(22)}$, essa característica é desejável em forrageiras sob pastejo, pois as folhas são um componente morfológico de melhor valor nutritivo. 
Observou-se que os tratamentos de fonte mista (FSM) mostrou DVF maior que o FNR, prologando o tempo de vida das folhas. $\mathrm{O}$ fósforo promoveu melhores condições de sobrevivência das folhas, possivelmente graças ao melhor desenvolvimento das raízes, que absorveram maior quantidade de nutrientes e água do solo, evitando a translocação de nutrientes das folhas mais velhas e adiando o processo de senescência das folhas.

Observou-se um efeito positivo do FSM sobre a TApF e NFV do capim-piatã. O fornecimento de P neste tratamento aumentou essas variáveis acima de $100 \%$ em relação ao tratamento sem adubação fosfatada devido a maior concentração de $\mathrm{P}$ presente no solo (Tabela 2), que elevou a atividade meristemática e a produção de células. De acordo com Cecato et al. ${ }^{(23)}$, entre os nutrientes que interferem nas características morfogênicas, o P merece destaque por participar dos importantes processos metabólicos das plantas.

Observou-se efeito $(\mathrm{P}<0,05)$ da adubação nitrogenada na TxAp (Tabela 5), com aumento de 8,9\% no aparecimento de novos perfilhos nas plantas adubadas com nitrogênio. Nelson e Zarrough ${ }^{(24)}$ relataram o aumento no perfilhamento de plantas forrageiras decorrentes da alta disponibilidade de N. Os autores evidenciaram ainda a importância dessa prática no acúmulo de massa seca e persistência da pastagem. Observaram-se diferenças entre as fontes de $\mathrm{P}$ na dinâmica de perfilhamento do capim-piatã. Tal fato pode ser explicado devido à baixa eficiência agronômica dos fosfatos de rocha. A baixa disponibilidade de $\mathrm{P}$ diminui a emissão de folhas nos perfilhos, prejudicando o perfilhamento das plantas forrageiras ${ }^{(25)}$.

Tabela 5. Taxa de Aparecimento de Perfilhos (TxAp), Taxa de Mortalidade de Perfilhos (TxMor), Taxa de Sobrevivência de Perfilhos (TxSobr), Índice de Estabilidade de Perfilhos (IE) e Número total de perfilhos (Perfilhos) do capim-piatã adubados com fontes de fósforo de diferentes solubilidades na primavera e verão de 2013

\begin{tabular}{|c|c|c|c|c|c|c|c|c|}
\hline \multirow{3}{*}{ Característica } & \multicolumn{6}{|c|}{ Tratamentos } & \multirow{3}{*}{$\begin{array}{l}\text { C.V. } \\
(\%)\end{array}$} & \multirow{3}{*}{$\begin{array}{l}\text { Valor- } P \\
\text { Efeito } \mathrm{N}\end{array}$} \\
\hline & \multirow[b]{2}{*}{ Controle } & \multicolumn{3}{|c|}{ Fontes de Fósforo } & \multirow{2}{*}{$0 \mathrm{~kg} \mathrm{ha}^{-1} \mathrm{~N}$} & \multirow{2}{*}{$100 \mathrm{~kg} \mathrm{ha}^{-1}$} & & \\
\hline & & FNR & FSS & FSM & & & & \\
\hline \multicolumn{9}{|c|}{ Primavera } \\
\hline TxAp & 3,29 & $3,05 \mathrm{c}$ & $4,30 b^{8}$ & $5,74 \mathrm{a}^{*}$ & 3,92 & 4,27 & 4,95 & 0,01 \\
\hline TxMort & 3,74 & $1,93^{\mathrm{a}}$ & $2,44^{a}$ & $3,26^{2}$ & 2,6 & 3,08 & 37,27 & 0,42 \\
\hline TxSobr & 2,96 & $2,48^{a}$ & $3,14^{2}$ & $2,99^{2}$ & 3,12 & 2,57 & 41,46 & 0,29 \\
\hline IE & 0,90 & $0,72 b$ & $1,19 a b$ & $1,40^{2}$ & 1,20 & 0,90 & 38,71 & 0,16 \\
\hline Perfilhos & 37,16 & $38,9 c$ & $57,4 b^{8}$ & $70,7 \mathrm{a}^{*}$ & 50,3 & 51,8 & 4,01 & 0,19 \\
\hline \multicolumn{9}{|c|}{ Verão } \\
\hline TxAp & 4,46 & $3,82 \mathrm{c}^{*}$ & $5,80 \mathrm{~b}^{*}$ & $7,02 \mathrm{a}^{*}$ & 5,21 & 5,34 & 4,18 & 0,26 \\
\hline TxMort & 1,15 & $1,03^{\mathrm{a}}$ & $0,76 b^{*}$ & $0,15 \mathrm{c}^{*}$ & 0,71 & 0,83 & 11,42 & 0,02 \\
\hline TxSobr & 3,64 & $3,19 \mathrm{c}$ & $5,21 b^{*}$ & $6,98 \mathrm{a}^{*}$ & 4,65 & 4,85 & 10,90 & 0,47 \\
\hline IE & 1,41 & $1,08 \mathrm{c}$ & $2,53 b^{*}$ & $4,00 a^{*}$ & 2,17 & 2,34 & 8,99 & 0,15 \\
\hline Perfilhos & 39,70 & $38,5 \mathrm{c}$ & $72,5 \mathrm{~b}^{8}$ & $76,2 \mathrm{a}^{*}$ & 56,08 & 57,3 & 2,84 & 0,17 \\
\hline \multicolumn{9}{|c|}{ FNR: Fonte de Solubilidade Lenta; FSS: Fonte de Solubilidade Rápida e FSM: Fonte de Solubilidade Mista. } \\
\hline
\end{tabular}

O maior número de perfilhos no tratamento FSM em virtude do adequado fornecimento de Pinfluenciou na maior mortalidade das plantas do mesmo tratamento. Infere-se que a grande quantidade de perfilhos aumentou a competição por luz, nutriente e água entre eles, deixando-os mais competitivos.

Mesquita et al. ${ }^{(26)}$ observaram que a aplicação de P elevou a produção de massa forrageira e o número de perfilhos do capim-braquiária, evidenciando a importância da adubação fosfatada no estabelecimento de uma pastagem. As fontes de P também foram efetivas na TxSobr dos perfilhos, indica-se assim a adubação fosfatada com manejo estratégico para persistência e estabilidade das pastagens brasileira.

Existe uma correlação positiva entre as características estruturais e morfogênicas. A adubação com fonte mista de $\mathrm{P}$ (Tabela 4) incrementou a TApF, o que resultou em um maior incremento no 
aparecimento de perfilhos. Isso se deve ao fato de que, com o aparecimento de uma nova folha no perfilho, ocorre paralelamente o aparecimento de nova gema axilar, podendo gerar um novo perfilho. As condições climáticas durante o período experimental também estimularam o aparecimento de folhas e gemas axilares e, consequentemente, novos perfilhos.

Nos meses de primavera, com o clima predisponente ao crescimento da planta forrageira, perfilhos mais velhos geralmente apresentam maior senescência foliar, e são substituídos por perfilhos novos. Assim, o tratamento FSM proporcionou um equilíbrio entre as taxas de mortalidade e aparecimento de perfilhos, garantindo um melhor IE nesse tratamento.

Observou-se efeito $(\mathrm{P}<0,05)$ da adubação nitrogenada sobre a TxMort no verão (Tabela 5). A dinâmica de perfilhamento sofre influência das condições de manejo que é submetida e, desse modo, infere-se que a maior renovação dos tecidos influenciada pelo $\mathrm{N}$ e pela temperatura provocou esse aumento de 16,9\% na TxMort do capim-piatã. Santos et al. ${ }^{(15)}$ observaram que, no verão, os perfilhos velhos entram em senescência e morrem para serem substituídos por novos em virtude do maior fluxo de tecidos.

Morais et al. ${ }^{(27)}$ observaram uma maior TxMort do capim-braquiária adubado com maiores doses de $\mathrm{N}$. Os autores concluíram que essa alta mortalidade é necessária para a mantença e sobrevivência da planta no ecossistema. Ademais, a adubação nitrogenada torna-se indispensável para manter as pastagens estáveis nas diferentes estações do ano, mantendo seu valor nutritivo e produção de matéria seca.

As plantas que receberam o FSM apresentaram maior TxAp. A disponibilidade de P (Tabela 2) fornecido no tratamento elevou essa taxa em 58,3\% em relação às plantas não adubadas. Como já é sabido, o perfilhamento tem íntima ligação com demais fatores ambientais. Assim, Carvalho et al. ${ }^{(28)}$ afirmaram que um adequado suprimento de fósforo no solo é essencial no perfilhamento das gramíneas.

A produção a pasto necessita do aparecimento de novos perfilhos visto que a restauração do índice de área foliar após corte ou pastejo depende disso. A adubação fosfatada com fonte de solubilidade mista de (FSM) garantiu um equilíbrio entre o aparecimento e mortalidade de perfilho, proporcionando um IE elevado (Tabela 7), mantendo assim estável a produção de massa forrageira devido a maior emissão de folhas que potencializou a geração de novos perfilhos. O número de perfilhos no tratamento FSM foi 91,9\% superior à ausência de $\mathrm{P}$. Este aumento é explicado pela maior disponibilidade de P no solo (Tabela 2), necessário em diversos processos fisiológicos na planta.

Não houve interação das adubações nitrogenadas e as fontes de fósforo em nenhuma das características avaliadas, porém verificou-se efeito da adubação nitrogenada no TAlF, TApF e filocrono $(\mathrm{P}<0,05)$ do capim-piatã no outono (Tabela 6).

Aadubação nitrogenada foi efetiva para o aparecimento de novas folhas, maior alongamento das mesmas e filocrono. O nitrogênio é essencial em diversos processos fisiológicos da planta, especialmente nas zonas de alongamento e de divisão celular ${ }^{(29)}$. Esse maior alongamento e aparecimento de folhas possivelmente potencializou a produção forrageira e a captação de $l u z^{(8)}$.

Ao contrastar os tratamentos com fontes de fósforo de diferentes solubilidades notou-se proeminência do tratamento com solubilidade mista (FSM) na TAlF, TAlC, TApF e filocrono no outono. No inverno, o tratamento FSM obteve superioridade apenas na TAlF. Apesar disso, o tratamento com fonte solúvel (FSS), juntamente com o tratamento FSM, se mostrou eficaz em relação ao controle e a fonte de baixa solubilidade em ambas as estações. 
Tabela 6. Taxa de alongamento foliar (TAlF), taxa de alongamento de colmo (TAlC), duração de vida das folhas (DVF), número de folhas vivas (NFV), taxa de aparecimento foliar (TApF) e filocrono do capim-piatã implantado com fontes de fósforo de diferentes solubilidades e adubação nitrogenada no outono e inverno 2014

\begin{tabular}{|c|c|c|c|c|c|c|c|c|}
\hline \multirow{3}{*}{ Característica } & \multicolumn{6}{|c|}{ Tratamentos } & \multirow{3}{*}{$\begin{array}{l}\text { C.V. } \\
(\%) \\
\end{array}$} & \multirow{3}{*}{$\begin{array}{c}\text { Valor- } P \\
\text { Efeito do } \mathrm{N} \\
\end{array}$} \\
\hline & \multirow{2}{*}{ Controle } & \multicolumn{3}{|c|}{ Fontes de Fósforo } & \multirow{2}{*}{$0 \mathrm{~kg} \mathrm{ha}^{-1}$} & \multirow{2}{*}{$\begin{array}{l}100 \mathrm{~kg} \\
\mathrm{ha}^{-1} \mathrm{~N}\end{array}$} & & \\
\hline & & FSM & FNR & FSS & & & & \\
\hline \multicolumn{9}{|c|}{ Outono } \\
\hline TAlF $\left.(\mathrm{cm} \mathrm{dia})^{-1}\right)$ & 1,80 & $3,85 \mathrm{a}^{*}$ & $1,74 \mathrm{c}$ & $3,24 b^{*}$ & 2,73 & 2,58 & 1,69 & 0,0006 \\
\hline TAlC $(\mathrm{cm} \mathrm{dia-1)}$ & 0,32 & $1,20 \mathrm{a}^{*}$ & $0,45 \mathrm{c}$ & $0,74 \mathrm{~b}^{*}$ & 0,72 & 0,64 & 10,00 & 0,06 \\
\hline DVF (dias) & 90,85 & $102,85 \mathrm{a}^{*}$ & $75,35 \mathrm{~b}^{*}$ & $99,10 \mathrm{a}^{*}$ & 91,47 & 92,60 & 3,46 & 0,50 \\
\hline $\begin{array}{l}\text { NFV (número de } \\
\text { follhas vivas perfillho } \\
\text { ') }\end{array}$ & 1,70 & $4,45 \mathrm{a}^{*}$ & $2,45 \mathrm{~b}$ & $3,20 b^{*}$ & 2,95 & 2,95 & 18,00 & 1,00 \\
\hline TApF & 0,06 & $0,38 \mathrm{a}^{*}$ & $0,07 \mathrm{c}$ & $0,16 b^{*}$ & 0,19 & 0,15 & 14,12 & 0,01 \\
\hline TseF & 2,17 & $2,04^{2}$ & $2,61^{a}$ & $1,87^{\mathrm{a}}$ & 2,20 & 2,14 & 25,26 & 0,84 \\
\hline Filocrono & 10,34 & $18,06 \mathrm{a}^{*}$ & $9,70 \mathrm{c}$ & $14,09 b^{*}$ & 13,56 & 12,54 & 3,55 & 0,004 \\
\hline \multicolumn{9}{|c|}{ Inverno } \\
\hline TAlF $(\mathrm{cm} \mathrm{dia})$ & 1,82 & $3.54 \mathrm{a}^{*}$ & $0.94 c^{*}$ & $3.14 b^{*}$ & 2,39 & 2,33 & 8,63 & 0,54 \\
\hline TAlC $(\mathrm{cm} \mathrm{dia}-1)$ & 0,27 & $0.82 \mathrm{a}^{*}$ & $0.48 \mathrm{~b}$ & $1.03 \mathrm{a}^{*}$ & 0,73 & 0,56 & 29,65 & 0,11 \\
\hline DVF (dias) & 93,61 & $123.99 \mathrm{a}^{*}$ & $84.99 b$ & $118.99 \mathrm{a}^{*}$ & 105,85 & 104,93 & 8,71 & 0,84 \\
\hline $\begin{array}{c}\text { NFV (número de } \\
\text { follhas vivas perfilho } \\
\text { ') }\end{array}$ & 2,31 & $5.56 \mathrm{a}^{*}$ & $2.56 \mathrm{~b}$ & $5.06 \mathrm{a}^{*}$ & 3,93 & 3,81 & 19,67 & 0,75 \\
\hline TApF & 0,06 & $0.18^{\mathrm{a}}$ & $0.10^{\mathrm{a}}$ & $0.13^{\mathrm{a}}$ & 0,12 & 0,11 & 56,44 & 0,83 \\
\hline TseF & 1,28 & $0.83^{\mathrm{a}}$ & $1.6^{\mathrm{a}}$ & $1.19^{\mathrm{a}}$ & 1,27 & 1,18 & 38,85 & 0,75 \\
\hline Filocrono & 10,2 & $14.76 \mathrm{a}^{*}$ & $11.02 \mathrm{~b}$ & 13.28ab* & 12,60 & 12,03 & 10,83 & 0,43 \\
\hline \multicolumn{9}{|c|}{$\begin{array}{l}\text { FNR: Fonte de Solubilidade Lenta; FSS: Fonte de Solubilidade Rápida e FSM: Fonte de Solubilidade Mista. } \\
{ }^{1} \text { Médias de Fontes de fósforo seguidas de um * diferem do tratamento controle pelo teste de Dunnet ao nivel de } 5 \% \text {. }\end{array}$} \\
\hline 20 & fósforo segr & das de letras: & 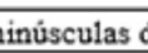 & 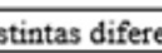 & (. & & & \\
\hline
\end{tabular}

Não houve efeito $(\mathrm{P}>0,05)$ da adubação nitrogenada na dinâmica de perfilhos do capim-piatã no outono e inverno (Tabela 7). A fonte de solubilidade mista favoreceu o aparecimento, sobrevivência e o índice de estabilidade de perfilhos do capim-piatã nas duas estações estudadas. Entretanto, a fonte de baixa solubilidade elevou a taxa de mortalidade dos perfilhos, evidenciando-se ainda mais a importância do fósforo para a manutenção e estabilidade da pastagem.

Houve efeito da adubação nitrogenada no capim-piatã apenas na primavera e na variável interceptação luminosa. Porém, não houve efeito $(\mathrm{P}>0,05)$ da adubação nitrogenada no índice de área foliar, interceptação luminosa e extensão luminosa do capim-piatã durante o verão, outono e inverno (Tabela $8)$.

$\mathrm{Na}$ primavera e verão, as fontes de fósforo com solubilidade mista e rápida proporcionaram maior índice de área foliar. Contudo, nota-se que nesses tratamentos a interceptação luminosa ficou acima do ideal (95\%) e os tratamentos controle e FNR não atingiram a interceptação ótima.

Em relação às fontes de fósforo, o tratamento FSM foi superior aos demais no IAF em todas as estações avaliadas. Isso demonstra que, com $\mathrm{P}$ em maiores quantidades no solo, o capim-piatã apresentou maior crescimento e acúmulo de folhas, que resultou no aumento do IAF.

Quando comparado ao tratamento controle, os tratamentos com fontes solúveis de fósforo (FSM e 
FSS) apresentaram maiores IAF, resultante da rápida solubilização e utilização do P pelas plantas. Os bons resultados dessas fontes podem estar associados a maior efetividade no uso do P pela forrageira avaliada na TAlF e TApF.

Em consequência do maior IAF, também ocorreu uma maior interceptação de luz incidente (IL) pelas plantas nesses dois tratamentos nas duas estações do ano. O tratamento FNR apresentou resultados semelhantes ao tratamento sem adição de P. Infere-se que a baixa solubilidade dessa fonte, associada ao baixo teor de P na solução do solo, interferiram na baixa expressividade dessa variável.

Tabela 7. Taxa de Aparecimento de Perfilhos (TxAp), Taxa de Mortalidade de Perfilhos (TxMor), Taxa de Sobrevivência de Perfilhos (TxSobr), Índice de Estabilidade de Perfilhos (IE) e Número total de perfilhos (Perfilhos) do capim-piatã implantado com fontes de fósforo de diferentes solubilidades e adubação nitrogenada no outono e inverno 2014

\begin{tabular}{|c|c|c|c|c|c|c|c|c|}
\hline \multirow{3}{*}{ Característica } & \multicolumn{6}{|c|}{ Tratamentos } & \multirow{3}{*}{$\begin{array}{l}\text { C.v. } \\
(\%)\end{array}$} & \multirow{3}{*}{$\begin{array}{l}\text { Valor- } P \\
\text { Efeito } N\end{array}$} \\
\hline & \multirow{2}{*}{ Controle } & \multicolumn{3}{|c|}{ Fontes de Fósforo } & \multirow{2}{*}{$\underset{\mathrm{N}}{0 \mathrm{~kg} \mathrm{ha}^{-1}}$} & \multirow{2}{*}{$\begin{array}{l}100 \mathrm{~kg} \\
\mathrm{ha}^{-1} \mathrm{~N}\end{array}$} & & \\
\hline & & FH & FNR & SS & & & & \\
\hline & \multicolumn{8}{|c|}{ Outono } \\
\hline TxAp & 2,37 & $5.13 \mathrm{a}^{*}$ & $2.00 \mathrm{c}^{*}$ & $3.32 b^{*}$ & 3,22 & 3,19 & 2,60 & 0,40 \\
\hline TxMort & 1,15 & $0.54 c^{*}$ & $1.68 \mathrm{a}^{*}$ & $1.12 \mathrm{~b}$ & 1,22 & 1,03 & 17,90 & 0,10 \\
\hline TxSobr & 2,52 & $4.07 \mathrm{a}^{*}$ & $2.09 \mathrm{c}^{*}$ & $3.57 b^{*}$ & 3,02 & 3,12 & 3,81 & 0,14 \\
\hline IE & 0,60 & $1.78 \mathrm{a}^{*}$ & $0.45 c^{*}$ & $1.10 b^{*}$ & 0,97 & 1,00 & 3,51 & 0,18 \\
\hline \multirow[t]{2}{*}{ Perfilhos } & 32,91 & $59.66 \mathrm{a}^{*}$ & $28.66 c$ & $53.41 b^{*}$ & 43,54 & 43,79 & 7,40 & 0,88 \\
\hline & \multicolumn{8}{|c|}{ Inverno } \\
\hline TxAp & 2,32 & $5.22 \mathrm{a}^{*}$ & $2.02 \mathrm{c}$ & $3.62 b^{*}$ & 3,45 & 3,14 & 8,45 & 0,06 \\
\hline TxMort & 0,92 & $0.58^{\mathrm{a}}$ & $1.05^{\mathrm{a}}$ & $1.07 \mathrm{a}$ & 0,99 & 0,82 & 51,35 & 0,49 \\
\hline TxSobr & 4,37 & $7.54 \mathrm{a}^{*}$ & $3.81 \mathrm{c}$ & $5.49 b^{*}$ & 5,26 & 5,34 & 8,59 & 0,73 \\
\hline IE & 1,04 & $3.36 \mathrm{a}^{*}$ & $0.82 \mathrm{c}$ & $1.84 \mathrm{~b}^{*}$ & 1,82 & 1,70 & 14,35 & 0,38 \\
\hline Perfilhos & 33,02 & $67.52 \mathrm{a}^{*}$ & $35.02 \mathrm{c}$ & $53.77 \mathrm{~b}^{*}$ & 47,14 & 47,52 & 4,45 & 0,73 \\
\hline \multicolumn{9}{|c|}{$\begin{array}{l}\text { FNR: Fonte de Solubilidade Lenta; FSS: Fonte de Solubilidade Rápida e FSM: Fonte de Solubilidade Mista. } \\
{ }^{1} \text { Médias de Fontes de fósforo seguidas de um * diferem do tratamento controle pelo teste de Dunnet ao nivel de } 5 \% .\end{array}$} \\
\hline${ }^{2}$ Médias de Fontes & e fósforo seg & uidas de letr: & minúscule & distintas di & erem entre & i pelo tes & "t" ao ní & de $5 \%$ \\
\hline
\end{tabular}

Os resultados das variáveis IL e Extlum nos tratamentos controle e fonte de fósforo de solubilidade lenta não diferiram entre si nas estações estudadas. A falta de expressividade do tratamento FNR pode ser justificado pelo $\mathrm{pH}$ do solo. Para Cabral et al. ${ }^{(30)}$, a liberação gradual do $\mathrm{P}$ dos fosfatos naturais é dependente do $\mathrm{pH}$ uma vez que, em solos ácidos, ocorre maior solubilização do P. No entanto, nos tratamentos com fósforo solúvel, essas variáveis apresentaram-se semelhantes e superiores, e isso demonstra a importância e eficiência do fósforo no desenvolvimento e produtividade de plantas forrageiras independente da época do ano. 
Tabela 8. Índice de área foliar (IAF), interceptação luminosa (IL) e extensão luminosa (Extlum) do capim-piatã implantado com fontes de fósforo de diferentes solubilidades e adubação nitrogenada no outono e inverno 2014

\begin{tabular}{|c|c|c|c|c|c|c|c|c|}
\hline \multirow{3}{*}{ Característica } & \multicolumn{6}{|c|}{ Tratamentos } & \multirow{3}{*}{ C.V. } & \multirow{3}{*}{$\begin{array}{l}\text { Valor-P } \\
\text { Efeito N }\end{array}$} \\
\hline & \multirow{2}{*}{ Controle } & \multicolumn{3}{|c|}{ Fontes de Fósforo } & \multirow{2}{*}{$0 \mathrm{~kg} \mathrm{ha}^{-1} \mathrm{~N}$} & \multirow{2}{*}{$100 \mathrm{~kg} \mathrm{ha}^{-1}$} & & \\
\hline & & FH & FNR & SS & & & & \\
\hline \multicolumn{9}{|c|}{ Primavera } \\
\hline IAF & 1,13 & $3.24 \mathrm{a}^{*}$ & $0.99 \mathrm{c}$ & $3.72 b^{*}$ & 1,48 & 1,56 & 7,94 & 0,22 \\
\hline II & 83,61 & $99.36 \mathrm{a}^{*}$ & $82.58 \mathrm{~b}$ & $97.21 \mathrm{a}^{*}$ & 89,53 & 91,85 & 1,40 & 0,01 \\
\hline Extlum & 0,76 & $0.34 b^{*}$ & $0.83^{2}$ & $0.40 b^{*}$ & 0,56 & 0,60 & 20,63 & 0,58 \\
\hline \multicolumn{9}{|c|}{ Verão } \\
\hline IAF & 3,04 & $4.66 \mathrm{a}^{*}$ & $3.01 \mathrm{c}$ & $4.96 b^{*}$ & 4,55 & 4,29 & 5,62 & 0,07 \\
\hline II & 89,57 & $99.44 \mathrm{a}^{*}$ & $90.52 b$ & $98.82 \mathrm{a}^{*}$ & 94,78 & 94,39 & 1,43 & 0,58 \\
\hline Extlum & 0,29 & $0.12 b^{*}$ & $0.25^{2}$ & $0.15 b^{*}$ & 0,18 & 0,22 & 18,89 & 0,09 \\
\hline \multicolumn{9}{|c|}{ Outono } \\
\hline IAF & 2,20 & $4.80 \mathrm{a}^{*}$ & $2.33 c$ & $3.68 \mathrm{~b}^{*}$ & 3,15 & 3,35 & 9,72 & 0,25 \\
\hline II & 82,88 & $98.83 \mathrm{a}^{*}$ & $82.58 b$ & $97.86 \mathrm{a}^{*}$ & 91,01 & 90,07 & 1,22 & 0,14 \\
\hline Extlum & 0,45 & $0.17 b^{*}$ & $0.40^{2}$ & $0.22 b^{*}$ & 0,29 & 0,33 & 24,41 & 0,29 \\
\hline \multicolumn{9}{|c|}{ Inverno } \\
\hline IAF & 1,17 & $2.77 \mathrm{a}^{*}$ & $1.42 \mathrm{c}$ & $2.21 b^{*}$ & 1,90 & 1,88 & 8,24 & 0,80 \\
\hline II & 84,45 & $95.93 \mathrm{a}^{*}$ & $82.05 b$ & $95.35 \mathrm{a}^{*}$ & 88,86 & 90,03 & 2,86 & 0,39 \\
\hline Extlum & 0,58 & $0.24 \mathrm{a}^{*}$ & $0.54 \mathrm{~b}$ & $0.29 \mathrm{a}^{*}$ & 0,42 & 0,40 & 14,45 & 0,50 \\
\hline \multicolumn{9}{|c|}{$\begin{array}{l}\text { FNR: Fonte de Solubilidade Lenta; FSS: Fonte de Solubilidade Rápida e FSM: Fonte de Solubilidade Mista. } \\
{ }^{1} \text { Médias de Fontes de fósforo seguidas de um * diferem do tratamento controle pelo teste de Dunnet ao nivel de } 5 \% \text {. }\end{array}$} \\
\hline \multicolumn{9}{|c|}{${ }^{2}$ Médias de Fontes de fósforo seguidas de letras minúsculas distintas diferem entre si pelo teste "t" ao nivel de $5 \%$. } \\
\hline
\end{tabular}

\section{Conclusão}

A utilização da fonte mista de fósforo e adubação nitrogenada proporcionaram melhorias na taxa de alongamento de folhas, de aparecimento de folhas, número de folhas vivas e rápida recuperação da altura pré-pastejo do capim-piatã. Assim, as adubações nitrogenada e fosfatada são alternativas para a persistência e competitividade da produção animal a pasto. Em relação à fonte, o uso de fontes de fósforo com solubilidade mista (lenta e rápida solubilidade) fornece esse nutriente a curto, médio e longo prazo, reduzindo o número de adubações e seus custos.

\section{Referências}

1. Pereira VV. A importância das características morfogênicas sobre o fluxo de tecidos do manejo de pastagens tropicais. Revista em Agronegócio e Meio Ambiente. 2013. 6:289-309. Avaible from: http://periodicos. unicesumar.edu.br/index.php/rama/article/view/2047/1939. Portuguese.

2. Ieiri AY, Lana, RMQ, Korndorfer GH, Pereira HS. Fontes, doses e modos de aplicação de fósforo na recuperação de pastagem com Brachiaria. Ciência e Agrotecnologia. 2010. 34:1154-1160. Avaible from: http:// dx.doi.org/10.1590/S1413-70542010000500011. Portuguese.

3. Santos GG, Silveira PM, Marchao RL, Petter FA, Becquer T. Atributos químicos e estabilidade de agregados sob diferentes culturas de cobertura em Latossolo do cerrado. Revista Brasileira de Engenharia Agrícola e 
Ambiental. 2012. 16:12-23. Avaible from: http://dx.doi.org/10.1590/S1415-43662012001100005. Portuguese.

4. Cecato U, Jobim CC, Rego FC. Sistema radicular: componente esquecido das pastagens. In: Simpósio Sobre Manejo Estratégico Da Pastagem. 2nd ed. Viçosa: Viçosa; 2004. p.159. Potuguese.

5. Santos DC. Características do capim-piatã e desempenho de bovinos em sistemas silvipastoris no cerrado brasileiro. [Tese] Escola de Veterinária e Zootecnia: Universidade Federal de Goiás; 2016. Disponível em: http://repositorio.bc.ufg.br/tede/handle/tede/5844. Portuguese.

6. Bahmani I, Thom ER, Matthew C. Tiller dynamics of perennial ryegrass cultivars derived from different New Zealand ecotypes: effects of cultivar, season, nitrogen fertilizer, and irrigation. Australian Journal Agricultural Research. 2003. 54:803-817. Avaible from: https://doi.org/10.1071/AR02135\#sthash.htFz2kLP.dpuf. English.

7. Malavolta, E. Manual de nutrição mineral de plantas. 2st ed. Agronômica Ceres, 2006. 638p. Portuguese.

8. Martuscello JA, Oliveira AB, Cunha DNFV, Amorim PL, Dantas PAL, Lima DA. Produção de biomassa e morfogênese do capim-braquiária cultivado sob doses de nitrogênio ou consorciado com leguminosas. Revista Brasileira de Saúde e Produção Animal. 2011. 12:923-934. Avaible from: http://revistas.ufba.br/index.php/ rbspa/article/view/2225/1161. Portuguese.

9. Sales ECJ, Reis ST, Rocha Júnior VR, Monção FP, Matos VM, Pereira DA, Aguiar ACR, Antunes APS. Características morfogênicas e estruturais da Brachiaria brizantha cv. Marandu submetida a diferentes doses de nitrogênio e alturas de resíduos. Semina: Ciências Agrarias. 2014. 35:2673-2684. Avaible from: http:// dx.doi.org/10.5433/1679-0359.2014v35n5p2673. Portuguese.

10. Costa KAP, França AFS, Oliveira IP. Produção de massa seca, eficiência e recuperação do nitrogênio e enxofre pelo capim Tanzânia adubado com nitrogênio, potássio e enxofre. Revista Ciência Agrotecnologia. 2005. 29:598-603. Avaible from: http://dx.doi.org/10.1590/S1413-70542005000300013. Portuguese.

11. Fagundes JL, Fonseca DM, Mistura C. Acúmulo de forragem em pastos de Brachiaria decumbens adubados com nitrogênio. Revista Brasileira de Zootecnia. 2006. 35:21-29. Avaible from: http://dx.doi.org/10.1590/ S0100-204X2005000400012. Portuguese.

12. Grant PR. Patterns of growth in Darwin's finches. Proceedings of the Royal Society of London. 1981. 212: 403-432. (Impresso).

13. Lemaire G, Chapman DF. Tissue flows in grazed plant communities. In: The ecology and management of grazing systems. 2nd ed. Wallingford: UK, 1996. p. 3-12. English

14. Zoz T, Lana MC, Steiner F, Frandoloso JF, Fey R. Influência do pH do solo e de fertilizantes fosfatados sobre a adsorção de fósforo em Latossolo Vermelho. Synergismus Scyentifica. 2009. 4:1-4. Portuguese.

15. Santos EDG, Paulino MF, Queiroz DS. Avaliação de pastagem diferida de Brachiaria decumbens Stapf. disponibilidade de forragem e desempenho animal durante a seca. Revista Brasileira de Zootecnia. 2009. 33:214-224. Avaible from: http://www.scielo.br/pdf/rbz/v33n1/a25v33n1.pdf. Portuguese.

16. Marschner H. Mineral nutrition of higher plants. 2nd ed. Academic Press: London, 1995. p. 889-899. English

17. Skinner RH, Nelson CJ. Elongation of the grass leaf and its relationship to the phyllochron. Crop Science. 1995. 35:4-10. Avaible from: DOI: http://dx.doi.org/10.2135/cropsci1995.0011183X003500010002x. English.

18. Volenec JJ, Nelson CJ. Responses of Tall fescue leaf meristems to $\mathrm{N}$ fertilization and harvest frequency. Crop Science. 1983. 23:720-724. Avaible from: DOI: http://dx.doi.org/10.2135/ cropsci1983.0011183X002300040028x. English.

19. Alexandrino E, Cândido MJD, Gomide JA. Fluxo de biomassa e taxa de acúmulo de forragem em capim Mombaça mantido sob diferentes alturas. Revista Brasileira de Saúde e Produção Animal. 2010. 12:59 71. Avaible from: http://revistas.ufba.br/index.php/rbspa/article/view/1956/1079. Portuguese. 
20. Dourado RL, Souza AL, Silva DRG. Respostas morfogênicas da Brachiaria brizantha cv. Piata submetida a doses de nitrogênio. In: Zootec, Aguas de Lindóia - SP, 2009. Anais. Aguas de Lindoia: UNESP, 2009, p. 29-33.

21. Teixeira FA, Pires AJV, Silva FF, Fries DD, Rezende CP, Costa ACPR, Santos TC, Nascimento PVN. Estratégias de adubação nitrogenada, características morfogênicas e estruturais em pastos de Brachiaria decumbens diferidos por 95 dias. Semina: Ciências Agrarias. 2014. 35:987-998. Avaible from: DOI: http:// dx.doi.org/10.4025/actascianimsci.v33i4.10212. Portuguese.

22. Santos MER, Barbero LM, Nascimento Junior D, Fonseca DM. Manejo do pastejo em sistemas de alto nível tecnológico. Belo Horizonte - Informe Agropecuário. 2008. 33, p. 7-14.

23. Cecato U, Skorobot VD, Fakir GM. Características morfogênicas do capim-mombaça (Panicum maximum Jacq. cv. Mombaça) adubado com fontes de fósforo, sob pastejo. Revista Brasileira de Zootecnia. 2007. 36:127133. Avaible from: http://dx.doi.org/10.1590/S1516-35982007000800001. Portuguese.

24. Nelson CJ, Zarrough KM. Tiller density and tiller weight as yield determinants of vegetative swards. In: Plant physiology and herbage production. London:UK, 1981, p.25-32.

25. Rodrigues D, Andrade FH, Goudriann J. Effects of phosphorus nutrition on tiller emergence in wheat. Plant and Soil, Dorducht. 1999. 209:283-295. Avaible from: doi: http://dx.doi.org/10.1023/A:1004690404870. English.

26. Mesquita FO, Cavalcante LF, Rebequi AM. Produção de mudas de maracujazeiro amarelo em substrato com biofertilizante bovino irrigado com águas salinas. Rev Agropec Tec. 2010. 31:134-142. Avaible from: http://www.scielo.org.ar/scielo.php?script=sci_arttext\&pid=S1850-20672012000100004. Portuguese.

27. Morais A, Favaretto N, Lang CR, Carvalho, PCF. Conservação do solo e da água em pastagens. In: Simpósio Sobre Manejo Estratégico Da Pastagem, Viçosa - MG, 2006. Anais. Viçosa: UFV, 2006, p. 110-115. Portuguese

28. Carvalho PC, Genro FTCM, Gonçalves EM. A estrutura do pasto como conceito de manejo: reflexos sobre o consumo e a produtividade. In: Simpósio sobre volumosos na produção de ruminantes, Jaboticabal - SP, 2005 . Anais. Jaboticabal: UNESP, 2005 p.107-114. Portuguese.

29. Martuscello JA, Silva LP, Cunha DNFV, Batista ACS, Ferreira PS. Adubação nitrogenada em capimmassai: morfogênese e produção. Ciência Animal Brasileira. 2015. 16:1-5. Avaible from: http://dx.doi. org/10.1590/1089-68916i118730. Portuguese.

30. Cabral CEA, Cabral LS, Bonfim-Silva EM, Carvalho KS, Kroth BE, Cabral HA. Resposta da Brachiaria brizantha $\mathrm{cv}$. Marandu a fertilizantes nitrogenados associados ao fosfato natural reativo. Comunicata Scientiae. 2016. 7(1): 66-72. Avaible from: http://dx.doi.org/10.17523/bia.v74n1p9. Portuguese. 